\title{
ALGUMAS CONCEPÇÕES SOBRE A RESOLUÇÃO DE PROBLEMAS E SUA UTILIZAÇÃO COMO ESTRATÉGIA DE ENSINO DE MATEMÁTICA
}

\section{SOME CONCEPTIONS ON PROBLEM SOLVING AND ITS USES AS MATHEMATICS TEACHING STRATEGY}

\section{Maria Alice Veiga Ferreira de Souza}

Instituto Federal do Espírito Santo

E-mail: alicevfs@hotmail.com, mariaalice@ifes.edu.br

\section{Sotério Ferreira de Souza}

Universidade Federal do Espírito Santo

E-mail: soterio.souza@hotmail.com

\section{Resumo}

As concepções dos professores sobre a utilização da resolução de problemas (RP) como via de aprendizagem de conteúdos, aplicação de conhecimentos ou como fator motivacional podem indicar e possivelmente justificar sua adesão nas aulas de Matemática. Por isso, este trabalho objetivou investigar as concepções de professores sobre a RP e sua utilização como estratégia de ensino, e integra uma investigação mais ampla em andamento, que versa sobre a formação de professores em RP. O estudo qualitativo foi realizado com dez professores de Matemática que atuam em diferentes níveis escolares. Os dados emergiram de um questionário com 43 itens, dos quais nove foram apresentados e discutidos. Os resultados apontaram desconhecimento de gestão de aulas baseadas em RP, apesar de eles reconhecerem as vantagens da RP como estratégia didático-pedagógica.

Palavras-chave: concepções. prática. resolução de problemas. ensino de Matemática.

\section{Abstract}

The conceptions of teachers about the uses of solving problems (SP) as a means of learning content, application of knowledge or as a motivational factor may indicate and possibly justify their adherences in Mathematics classes. The objective was to investigate teachers' conceptions of the SP and its uses as a teaching strategy, as part of a larger ongoing investigation, which deals with teacher training in SP. The qualitative study was carried out with ten Mathematics teachers working in different educational levels. The data emerged from a questionnaire with 43 items, of which it is presented and discussed up 9. The results showed classes based on SP management of ignorance, although they recognized its advantages as didactic and pedagogical strategy.

Palavras-chave: concepts. practice. problem-solving. Mathematics teaching. 


\section{INTRODUÇÃO}

As concepções dos professores sobre diferentes aspectos ligados ao ensino, à aprendizagem, aos conteúdos escolares e ao ambiente educacional geralmente podem contribuir para explicar a atuação deles em sala de aula. Isso porque integram o pensamento humano que, por sua vez, influencia significativamente o que é feito. As concepções do professor, portanto, podem torná-lo mais ou menos receptivo, por exemplo, à utilização da Resolução de Problemas (RP) como via de aprendizagem de conteúdos de Matemática, aplicação de conhecimentos ou mesmo fator motivacional para o estudo da Matemática.

A utilização da RP em sala de aula foi defendida por diferentes matemáticos e investigadores - Schoenfeld (1985; 1992; 1996), Pólya (1945; 1981) e Guimarães (2005), por exemplo. No entanto, ainda não se estabeleceu entre os professores de matemática uma postura de apoio a sua utilização em sala de aula em todas as situações acima mencionadas - via de aprendizagem de conteúdos, aplicação de conhecimentos, ou motivação para o estudo de Matemática, assim também denominadas por esses autores.

A baixa frequência de um trabalho em RP, nos moldes aqui delineados, nas aulas de Matemática pode ser explicada por fatores ligados ao problema exposto e à condição de gestão de uma RP. Dos problemas pode-se dizer que, apesar de fascinantes, resolvê-los não é tarefa fácil e nem trivial, dada sua singularidade, pois, se assim não for, não é possível falar em problema, mas em exercício, na visão de Pólya (1945; 1981). Pelo lado do gestor, é necessário praticar e desenvolver um estilo idiossincrático de conduzir a resolução de problemas com os alunos. Resolver um problema é delinear uma estratégia para encontrar uma solução ou resposta para uma questão que ainda não dispõe de um algoritmo ou de uma estratégia antes aprendida. Assim, a tarefa de RP não se reduz à aplicação de regras internalizadas. Pelo contrário, é algo sempre realizado pela primeira vez e pela qual se invoca todo o arcabouço teórico e prático adquiridos para sua solução, concordando com Abrantes (1989). 
Porém, a imprevisibilidade no trabalho do professor ao gerir uma RP em aulas de Matemática pode ser um fator que o afaste desse tipo de atividade. É preciso prever, por exemplo, as dúvidas e as respostas dos alunos para que a gestão seja facilitada e planejada de modo a conduzi-los para a solução. É útil, portanto, ampliar a visão sobre o problema, experimentando diferentes caminhos para solucioná-lo, o que torna fundamental o planejamento de uma proposta metodológica nesse sentido. Entretanto, outras perspectivas de solução podem surgir ao longo de sua aplicação em sala de aula, e sua gestão virá apenas com a prática em sala de aula.

Desse modo, a experiência na gestão de sala de aula traz para o primeiro plano conhecimentos somente adquiridos no contexto dessa prática. É o que defendem os autores Schön (1991; 1992), Elbaz (1983), Fenstermacher (1994) e Clandinin (1985; 1986) quando afirmam que a prática letiva faz emergir aspectos ligados ao pensamento, às reflexões, aos desejos e aos propósitos do futuro professor. São, dessa forma, contrários à ideia de uma racionalidade técnica na qual o conhecimento profissional ocorre pela aplicação pura e simples do conhecimento científico e técnico ao contexto prático. Particularmente, Schön (1991; 1992) afirma existir nesse contexto prático da docência: 1- um conhecimento na ação - conhecimento emerso na prática; 2- uma reflexão na ação - pensar sobre o que se faz, enquanto se faz e; 3- uma reflexão sobre a ação - pensar sobre o que se fez.

Nessa direção, este artigo apresenta os primeiros resultados de uma pesquisa mais ampla e em andamento sobre as práticas de professores de Matemática com a RP, tendo como primeira etapa uma investigação a respeito das concepções apresentadas por dez professores de Matemática sobre essa prática em sala de aula de Matemática. Esta se encontra traduzida na seguinte pergunta de investigação: quais concepções os professores de Matemática apresentam acerca dos usos da RP como via de ensino de conteúdos ou como fator motivacional para seus estudantes? O objetivo perseguido para essa etapa foi o de conhecer as concepções de professores sobre a prática da resolução de problemas realizada em sala de aula de Matemática nas diferentes modalidades. 


\section{APOIO TEÓRICO E RECVISÃO DE LITERATURA}

A comunidade de investigadores matemáticos americanos que participam do National Council of Teachers of Mathematics declarou em 1980 (NCTM, 1980) que a resolução de problemas deveria ser o foco da Matemática escolar. Essa comunidade vem sendo referência em assuntos de ensino e de aprendizagem de Matemática em nível mundial, e essa declaração obteve uma grande adesão no mundo todo. Apesar de a forte defesa desses investigadores pelo uso da RP em sala de aula, essa proposta não refletiu na prática docente, pelo menos, não como se desejava originalmente. No máximo, alguns poucos professores aplicaram essa ideia em problemas do tipo truque ou em métodos rotineiros que não elevaram o trabalho mental ao nível proposto.

Os motivos para a não aplicação provavelmente foram os mesmos dos atuais: 1- dificuldade de aplicação em função do caráter de imprevisibilidade e de insegurança geradas pela própria resolução de um problema, aqui entendido como Pólya (1945) - questão que se deseja responder ou resolver, mas não se dispõe previamente de uma estratégia conhecida para fazê-lo; 2- ausência de um trabalho direcionado para essa finalidade na formação de professores; 3- concepções sobre o que seja o ensino e a aprendizagem de Matemática, para citar alguns.

Contudo, é possível afirmar que as concepções exercem alguma influência sobre a prática docente por integrar o conhecimento do professor e, assim, influenciar seus fazeres. Conhecer suas concepções implica em ter acesso à vida mental que, por sua vez, gerencia seus comportamentos. E, como este trabalho define as concepções dos professores de Matemática? Thompson assume que as concepções são constituídas por crenças, pontos de vista e conceitos e formam uma organização complexa de uma estrutura mental mais completa, que orienta a pessoa na sua relação com outras pessoas, com objetos e com as situações de mundo, predispondo-a ao agir.

Para Thompson (1992), o ser humano possui diferentes graus de convicção e é justamente 
nesse ponto que ela difere crença de conhecimento. Acreditar mais fortemente em certas coisas do que em outras interfere no quanto essas crenças podem ou não ser mutáveis. Por outro lado, o conhecimento não admite essa variabilidade. Como explica Guimarães (2010), “... dizemos que conhecemos um facto, um acontecimento, uma situação, muito ou pouco, completa ou incompletamente, mas não dizemos que o conhecemos com muita ou com pouca convicção".

A importância de conhecer inicialmente as conviç̧ões dos professores sobre a utilização da RP como método de ensino ocorre pelas oportunidades de se reverter concepções ainda situadas em graus mutáveis, se os professores apresentarem convicções limitadoras da prática da RP em sala de aula. Assim, o trabalho formativo apresentado na sequência a esse conhecimento (emerso do questionário) poderá (ou não) conduzi-los a refletir sobre suas práticas e, possivelmente, a alterar sua postura diante de um novo método de ensino de conteúdos matemáticos. Essa verificação virá, ao final do curso de extensão, com uma entrevista semiestruturada.

Mas, quais conhecimentos os professores deveriam/poderiam apreender para alcançar mais segurança no trabalho de sala de aula com os problemas? Uma possibilidade seria dominar as heurísticas propostas por Pólya (1945), que são os métodos de resolução de problemas. Para Pólya (1945), há quatro fases na resolução de qualquer problema de Matemática: a compreensão do problema, o planejamento, a execução e a retrospectiva (ou looking back). Compreender um problema implica em identificar as partes principais do texto: a incógnita, os dados, a condicionante. É preciso nesse ínterim considerar a familiaridade do sujeito com conhecimentos que já deveria possuir sobre o tema do problema, mesmo que superficiais, e o aperfeiçoamento da compreensão, que significa traçar associações com o conhecimento prévio que ele já possui.

O planejamento é o principal feito em todo o processo de resolução. Trata-se do roteiro geral a ser seguido. Um bom plano tem base na experiência passada e em conhecimentos 
previamente adquiridos. A construção do plano depende de relembrar fatos matemáticos importantes, como problemas já resolvidos ou teoremas provados. A próxima fase é a da execução do plano anteriormente traçado, que parece contar mais com a concentração do que com a angústia da procura por um bom plano. Uma análise retrospectiva de todas as fases anteriores engloba a execução, na qual se verificará se o resultado final atendeu aos requisitos do problema, por exemplo.

Apesar de serem fases distintas e com exigências particulares para o solucionador, elas não ocorrem isoladamente, mas de maneira integrada, uma ocorrendo mais em primeiro plano do que a outra, a depender do estágio atual do processo de resolução. Pólya $(1945 ; 1981)$ não apenas enuncia as quatro fases, mas também mostra como o professor deve conduzi-las, principalmente em duas obras: How to solve it e Mathematical Discovery. Essas obras são um convite à prática da RP pelo professor em sala de aula.

Nessa abordagem, a prática proporcionará maturidade e experiência ao docente, capacidade de conferir maior domínio sobre a imprevisibilidade gerada na aplicação de um problema como método de ensino, além de diminuir a insegurança temida por muitos. Isso porque a Matemática praticada pelas heurísticas apresenta-se como indutiva e experimental, ao contrário da Matemática Euclidiana, que tende para o lado dedutivo e de sistematização (SOUZA \& GUIMARÃES, 2015a; 2015b). Assim, a prática profissional pode contribuir para o conhecimento ao promover e estimular competências que somente por ela seria possível. A esse respeito, Ponte (2004) cita as três grandes áreas de formação do professor de Matemática enumeradas pelo NCTM: a formação matemática, a formação para o ensino da Matemática e a formação prática. Há, portanto, certo peso atribuído à formação prática docente, concedido pela comunidade de educadores matemáticos.

É útil considerar a prática letiva não apenas como lugar de 'aplicação', mas também e, sobretudo como lugar de produção de conhecimentos. Essa prática coloca à frente aspectos ligados ao pensamento, às reflexões e aos desejos e propósitos do professor, assim 
entendidos por Schön (1991; 1992), Elbaz (1983), Fenstermacher (1994) e Clandinin (1985; 1986), que afirmam existir um conhecimento específico do professor emergente da prática letiva, constituído e desenvolvido em íntima relação com essa prática, opondo-se assim ao senso comum de ver o professor como alguém destituído de um saber próprio: "os professores", diz Clandinin "são vistos como possuindo experiência mas não conhecimento" $(1986$, p.3)

A palavra "experiência" vem aqui impregnada dos sentidos atribuídos por Larrosa (2002), para quem a experiência não é o que acontece, mas sim "o que nos acontece" ou "o que nos toca". Desse modo, as experiências são sempre subjetivas, pessoais, individuais, situadas e contextualizadas, mesmo quando propiciadas por acontecimentos partilhados coletivamente. A experiência carrega em si a marca da imprevisibilidade. Não é uma meta a alcançar, nem um resultado esperado a ser perseguido, mas é, antes de tudo, um processo contínuo de produção de sentidos.

As constatações de Schön (1991; 1992), Elbaz (1983), Fenstermacher (1994), Clandinin (1985; 1986) e Larrosa (2002) sobre a dinamicidade do processo de constituição dos saberes docentes, e do lugar e do papel da prática nesse processo, se opõem à ideia de uma racionalidade técnica, que prega que o conhecimento profissional nada mais é do que a simples aplicação direta do conhecimento científico e técnico e das orientações das autoridades educativas ao contexto da prática.

Concorda-se com Schön (1991; 1992) sobre a existência nesse ínterim: 1- um conhecimento na ação - conhecimento emerso na prática; 2- uma reflexão na ação - pensar sobre o que se faz, enquanto se faz e; 3- uma reflexão sobre a ação - pensar sobre o que se fez. Tudo isso como objetivo de estimular ações direcionadas à formação docente: proporcionar experiências que revelem ao professor e permitam a ele desenvolver um repertório de conhecimentos e reflexões iniciais que possivelmente levariam muito tempo para ocorrer, se ocorrerem, ao longo de sua trajetória profissional. 
Com essa perspectiva, a investigação objetivou conhecer as concepções dos professores sobre os usos da RP como meio de aprendizagem ou como fator motivacional para seus alunos, para que, com base nessas concepções, seja possível inferir sobre suas práticas com ações formativas em RP como método. Por fim, objetivou também verificar os efeitos concretos sobre a prática do professor em sala de aula e possivelmente sobre suas próprias convicções a respeito do que seja a RP nos moldes aqui delineados. Limitou-se aqui, como afirmado, trazer os primeiros resultados, ou seja, a primeira etapa da investigação acima descrita. 


\section{MÉTODO E PROCEDIMENTOS}

A investigação como um todo está sendo conduzida no âmbito de um curso de extensão para formação de professores de Matemática em gestão de resolução de problemas em aulas de Matemática de todos os níveis escolares. Nesse percurso, emergem dados qualitativos sobre as variáveis trabalhadas com os professores ao longo do curso. Entre elas, as concepções sobre como praticam (ou poderiam praticar) a RP com seus alunos, aspecto de interesse neste estudo.

O curso de extensão está sendo realizado no Instituto Federal do Espírito Santo, Brasil, com 15 encontros semanais de duas horas em sala de aula reservada para esse fim, das 10 às $12 \mathrm{~h}$. Logo no primeiro encontro, sem qualquer intervenção inicial dos pesquisadores, os professores foram convidados a responder a um longo questionário com a finalidade de revelar algumas variáveis de interesse, além de outros aspectos como a formação e trajetória em Matemática, desconsiderados para este texto. Esse questionário foi submetido a um estudo piloto para verificar a validade dos questionamentos a fim de responder as perguntas de investigação, o qual foi realizado com professores de Matemática distintos dos que participaram efetivamente da amostra investigada.

Assim, nesta investigação participam 10 professores de Matemática de escolas públicas e privadas do Estado do Espírito Santo, de todos os níveis escolares, ou seja, desde o ensino básico ao superior. A reduzida quantidade de professores é proposital por envolver estudo da aplicação de resolução de problemas no ambiente escolar de cada professor, gerando gravações em vídeo, entrevistas e outros instrumentos imprescindíveis para as etapas posteriores à aplicação do questionário.

O questionário reuniu 43 itens com o objetivo principal de compreender/conhecer o perfil acadêmico e profissional dos dez professores, o que pensam e como praticam a RP como um resolvedor e como um gestor de RP em sala de aula. Dentre eles, destacam-se os de maior interesse para o presente trabalho: 
Item 1 - Quanto você acha que a RP deveria integrar suas aulas de Matemática. Por quê?

Item 2 - Quanto você acha que a RP integrou as aulas de Matemática que você ministrou até hoje? Por quê?

Item 3 - Você acredita que um problema pode iniciar algum novo assunto de Matemática? Por quê?

Item 4 - Se você deseja trabalhar a RP em algum conteúdo escolar específico, em que momento ao longo do ensino desse conteúdo você usaria a RP? Por quê?

Item 5 - Quais critérios você usaria para selecionar problemas para serem usados ao longo do ensino de algum conteúdo da Matemática escolar?

Item 6 - Se você trabalha ou trabalhou a RP com seus alunos, descreva como você planejou essas aulas desde a escolha do problema até a avaliação.

Item 7 - Pesquisas em diversos países do mundo apontam que a maioria dos professores, nos diversos níveis de ensino, não utiliza a RP de maneira frequente em suas aulas. Em sua opinião, quais poderiam ser as causas desse fato?

Item 8 - Em qual(is) etapa(s) (compreensão, planejamento, execução e verificação/retrospectiva) você encontra facilidades/dificuldades na resolução de um problema?

Item 9 - Que facilidades/dificuldades você encontra ao trabalhar a resolução de problemas com seus alunos?

Os participantes da investigação conheciam os propósitos dos instrumentos de coleta de dados e os fins científicos do desenvolvimento do curso de extensão. Ademais, todos os participantes assinaram Termo de Consentimento Livre e Esclarecido, aceitando que seus registros escritos e falados fossem incluídos na pesquisa e divulgados em meio acadêmicocientífico sem, contudo, revelar suas identidades, exceto por nomes fictícios. Toda a investigação transcorreu sob rígida vigilância de aspectos minimizadores de riscos de qualquer ordem para os sujeitos. 


\section{RESULTADOS E DISCUSSÃO}

Os professores pareceram compreender que a RP precisa integrar frequentemente (50\%) ou sempre (50\%) as aulas por eles ministradas ao serem questionados "quanto você acha que a RP deveria integrar suas aulas de Matemática e por quê?". Apesar de concordar que a RP deve compor as aulas, as justificativas para essas respostas, no entanto, foram bem diversificadas. Um professor entendeu a RP como fator motivacional, três como objeto de aplicação de conteúdos e dois como via de aprendizagem de conteúdos, aspectos discutidos por Schön (1991; 1992). Os restantes afirmaram que nada justificava utilizar a RP em suas aulas. Esse resultado forneceu indícios de que alguns professores $(60 \%)$ observam alguma utilidade didático-pedagógica para o uso de RP em suas aulas, mesmo que com uma visão particionada: somente como fator motivacional ou como via de aprendizagem de conteúdos ou de aplicação de conhecimentos.

Apesar de afirmar que a RP deveria integrar as aulas, as respostas ao item "quanto você acha que a RP integrou as aulas de Matemática que você ministrou até hoje e por quê?" mostram que raramente (60\%) e às vezes (40\%) esse método de trabalho não é colocado em prática. As justificativas para as respostas giraram em torno da falta de tempo, do compromisso em cumprir os conteúdos escolares, da carência de compreensão e de interpretação de textos pelos alunos, além de declarar as próprias inseguranças e pouco conhecimento e reflexão sobre o tema. Essas justificativas reforçam o desconhecimento desses professores sobre a possibilidade de poder usar a RP como meio de aprendizagem. O tempo de aula e o compromisso em cumprir o currículo escolar não seriam justificativas plausíveis com replanejamentos de suas aulas. Referente à baixa compreensão dos textos dos problemas, mais uma vez desconheceram que a própria RP poderia promover essa compreensão, caso o professor soubesse conduzir esse tipo de discussão.

Ao serem questionados sobre "você acredita que um problema possa iniciar algum novo assunto de Matemática e por quê?", 70\% responderam "sempre" e 30\% "às vezes". A maioria afirmou que o trabalho inicial de um tema matemático com RP estimula a reflexão, discussão 
e levantamento de hipóteses, além de permitir realizar conexões com a realidade. Alguns ponderaram que nem todos os assuntos são de interesse dos alunos e deles mesmos, e que certos temas são de interesse meramente teórico.

Apesar de esses professores afirmarem que é possível iniciar um novo conteúdo matemático por um problema e, até mesmo demonstrarem conhecer vantagens de fazê-lo, a pesquisa de Redling (2011) mostrou que as ações dos professores são diversas de suas afirmações. Na realidade, Redling verificou que os conteúdos escolares eram formalizados previamente e os problemas eram utilizados para ilustrar os assuntos, o que não se caracteriza como usar a RP como via de aprendizagem, mas como aplicação de conteúdos, o que realmente deve vir após o assunto ter sido trabalhado.

A esse respeito, vale destacar a possível confusão feita sobre o que seja iniciar um novo assunto pela via da RP e aplicar um conteúdo para a RP. Pela via de aprendizagem, os sujeitos desconhecem o conteúdo a ser aprendido. A aprendizagem da Matemática ocorre em meio a uma situação problemática. Na aplicação, ao contrário, o conteúdo já foi aprendido e os sujeitos o aplicarão em uma situação problemática. A pesquisa de Redling (2011) levanta a hipótese de que a prática dos dez professores sobre a RP deve ser de aplicação e não como via de aprendizagem de conteúdos, como afirmaram. Contudo, essa hipótese poderá ser ou não confirmada na próxima fase da pesquisa mais ampla, quando praticarão a RP com seus alunos. No entanto, a pesquisa a desenvolver vai além da investigação de Redling, uma vez que a prática desses professores fomentará reflexões que serão experimentadas em outras aulas que envolvem a RP. É possível, assim, de acordo com Thompson (1992), a depender do grau de convicção, que as concepções deles sejam alteradas, o que possivelmente será conhecido no final desta investigação quando forem entrevistados.

Na sequência, foi perguntado aos professores em que momento ao longo do ensino de certo conteúdo ele trabalharia a RP e por quê. $60 \%$ dos professores disseram que trabalhariam a RP no início da abordagem do conteúdo. Dois afirmaram poder usar o método em qualquer 
altura do ensino e um respondeu com base nas vantagens em se trabalhar a RP. Mais uma vez, seis professores destacaram o uso da RP no início de um novo conteúdo. Outros dois ampliaram suas perspectivas de uso durante e ao final do estudo de um conteúdo matemático.

Os professores foram questionados sobre quais critérios utilizariam para selecionar problemas a serem aplicados ao longo do ensino de algum conteúdo da Matemática escolar. As respostas foram de dois tipos: uma com foco nos alunos - pela idade escolar, pela realidade sócio-cultural-intelectual, pela compatibilidade com a série escolar e pelos conhecimentos prévios; outra com foco nos problemas - pela criatividade, por serem motivadores, pela relevância. Esses critérios, de fato, devem ser considerados quando da escolha de um problema para os alunos. O que preocupa é que eles foram dados por pessoas diferentes. Nenhum dos dez professores reuniu dois ou mais critérios, o que permite deduzir que há uma reduzida visão do que seja selecionar um bom problema, tal como dito por Abrantes (1989).

Posteriormente, foi solicitado, então, que eles relatassem o planejamento de uma aula de RP, desde a escolha do problema até a avaliação. Nove dos dez professores não souberam dizer como planejavam uma aula baseada em RP. Apenas um professor declarou realizar algumas aulas com essa abordagem, e das que ele ministrou, foi permitido à turma levantar possibilidades e discutir entre si, sem sua interferência, dedicando uma aula de 50 minutos para esse fim. Esse resultado reforça a necessidade de formação continuada baseada nos pressupostos levantados por Schön (1991; 1992), Elbaz (1983), Fenstermacher (1994) e Clandinin (1985; 1986), o que significa confrontar o conhecimento formal com o prático, o primeiro obtido recorrendo-se aos métodos científicos, e o segundo, desenvolvido com base nas ações realizadas e na reflexão feitas sobre elas.

Foi dito aos dez professores que pesquisas em diversos países do mundo apontam que a maioria dos professores, nos diversos níveis de ensino, não utiliza a RP de maneira frequente 
nas aulas. Em seguida, perguntou-se sobre quais motivos causaram esse fato. Alguns analisaram o lado do professor - pouca motivação, desconhecimento, falta de tempo e insegurança; outros, pelo lado do aluno - poucos sabem ler e interpretar, por comodismo, por desejar memorizar soluções; outros, ainda por ambos os lados.

Em seguida, o foco foi descobrir em qual(is) dessas etapa(s) (compreensão, planejamento, execução e verificação/retrospectiva) eles encontram facilidades/dificuldades na resolução de um problema. As respostas foram diversificadas, não se destacando nenhuma das quatro etapas como sendo mais fácil ou mais difícil na resolução de um problema. Resta descobrir se esses professores compreendem o que seja e o que devem praticar em cada uma das etapas. Como não souberam responder à pergunta sobre como planejam uma aula de RP, fica a dúvida sobre a localização de suas facilidades/dificuldades. Provavelmente, esse fato será revelado quando o planejamento de aulas de RP da investigação em curso for abordado.

Os professores foram ainda questionados sobre que facilidades/dificuldades encontravam ao trabalhar a resolução de problemas com os alunos. Pelo lado das dificuldades dos alunos, os professores relataram principalmente: desmotivação, falta de hábito de pesquisa e carência de interpretação. Pelo lado do professor, apontaram a insegurança em conduzir uma turma com esse método e a reduzida carga horária na disciplina. As facilidades foram raras, mas as apontadas não mostravam facilidades, e sim vantagens de se trabalhar com a RP.

Os resultados apresentados pelos dez professores dos nove questionamentos feitos reforçam a necessidade de um trabalho direcionado para a formação do professor em RP. Não qualquer formação, mas uma baseada no conhecimento na ação, na reflexão na ação e na reflexão sobre ação. 


\section{CONCLUSÕES}

O presente trabalho apresentou a primeira parte de uma investigação mais ampla e extensa e em andamento sobre as concepções em RP e sua utilização como estratégia de ensino de Matemática. Especificamente, o objetivo foi descobrir quais concepções os dez professores de Matemática apresentam a respeito da utilização da RP como meio de aprendizagem ou como fator motivacional para seus alunos, uma vez que suas convicções impactam sobre o próprio comportamento e, portanto, podem ser mais ou menos receptivos ao uso de RP como via didático-pedagógica.

Os resultados apontaram que, apesar de todos os professores afirmarem que a RP deveria integrar suas aulas de Matemática (item 1), na prática o oposto vem ocorrendo, ou seja, declararam que raramente o fazem ou, no máximo, às vezes (item 2). As justificativas giraram em torno da falta de tempo do docente, do compromisso em cumprir os conteúdos, de o aluno não compreender os textos, além de alguns professores confessarem inseguranças e falta de conhecimento, fato reforçado no item 7 e, de certo modo, no item 9. De acordo com os ensinamentos de Pólya, todas essas justificativas desapareceriam diante do conhecimento e da prática com reflexão das heurísticas por ele traçadas.

Esse desconhecimento poderá ser reforçado por uma possível confusão feita pelos sujeitos sobre o que seja iniciar algum novo assunto pela RP (item 3) e aplicar um conhecimento na RP, o que poderá ser confirmado ou não ao final da investigação mais ampla, quando planejarão aulas baseadas em RP. É possível que os resultados da pesquisa científica de Redling (2011) se repitam, ou seja, os professores afirmam realizar um trabalho em RP como via de aprendizagem, mas, na prática, formalizam os conteúdos e os aplicam em RP. Não obstante esse cenário, os professores, de maneira geral, pensam ser uma vantagem iniciar um novo conteúdo pela RP por estimular a reflexão, a discussão, o levantamento de hipóteses e a conexão com a realidade. Seis desses professores fortaleceram a possibilidade de iniciar um novo conteúdo pela via da RP no item 4. 
Os professores demonstraram possuir noções sobre como selecionar problemas para seus alunos (item 5). A preocupação reside em eles terem selecionado critérios isoladamente: ou por alguns aspectos ligados às características dos alunos, ou somente pelas características do problema. Melhor seria que reunissem todos esses elementos em seus critérios, além de outros aspectos igualmente importantes. A reduzida visão para a seleção de um problema se repetiu no planejamento de uma aula baseada em RP (item 6), quando nove dos dez professores deixaram em branco esse relato, em uma possível demonstração de desconhecimento, o que igualmente poderia justificar a diversidade de respostas do item 8 . A continuidade da investigação poderá confirmar ou não as hipóteses levantadas. 


\section{REFERÊNCIAS}

ABRANTES, P. Um (bom) problema (não) é (só)... Educação e Matemática, Lisboa, 8(4), 7-10, 1989.

CLANDININ, D. J. Classroom pratice, teacher images in action. Londres: The Falmer Press, 1986.

CLANDININ, D. J. Personal practical knowledge: a study of teacher's classroom images. Curriculum Inquiry, v. 14, n. 4, 361-385, 1985.

ELBAZ, F. Teacher thinking, a study of practical knowledge. Londres: Croom Helm, 1983.

FENSTERMACHER, G. The knower and the known: the nature of knowledge in research on teaching. Review of Research in Education, v. 20, 3-56, 1994.

GUIMARÃES, H. M. Concepções, crenças e conhecimento: afinidades e distinções essenciais. Quadrante, Lisboa, v. 19, n. 2, 227-254, 2010.

GUIMARÃES, H. M. A resolução de problemas no ensino da Matemática: alguns passos do seu percurso no discurso curricular em Portugal. Em: SANTOS, L. et al. (Org.). Educação e Matemática: caminhos e encruzilhadas. Lisboa: APM, 2005. 145-166.

LARROSA, J. Notas sobre a experiência e o saber da experiência. Revista Brasileira de Educação. n. 19, 2002.

NATIONAL COUNCIL OF TEACHERS OF MATHEMATICS. An agenda for action. Reston, VA: NCTM, 1980.

PÓLYA, G. How to solve it. Princeton, New Jersey: Princeton University Press, 1945.

PÓLYA, G. Mathematical discovery. New York, NY: Wiley, 1981.

PONTE, J. P. A formação matemática do professor: Uma agenda com questões para reflexão e investigação (intervenção no Painel "A Matemática e diferentes modelos de formação"). Em: BORRALHO, A.; MONTEIRO, C.; ESPADEIRO, R. (Orgs). A Matemática na formação do professor. Lisboa: Secção de Educação e Matemática da SPCE, 2004. 71-74.

REDLING, J. P. A Metodologia de resolução de Problemas: concepções e práticas pedagógicas de professores de matemática do ensino fundamental. 2011. Dissertação (Mestrado em Ciências) - Faculdade de Ciências, Universidade Estadual Paulista - UNESP, São Paulo, 2011.

SCHOENFELD, A. Por que toda essa agitação acerca da resolução de problemas? Em: ABRANTES, P.; LEAL, L. C. \& PONTE, J. P. (Orgs.). Investigar para aprender matemática. Lisboa: APM e Projecto MPT, 1996. 61-72. 
SCHOENFELD, A. H. Mathematical problem solving. New York, NY: Academic Press, 1985.

SCHOENFELD, A. H. Learning to think mathematically: problem solving, metacognition, and sense-making in mathematics. Em: GROUWS, D. (Org.). Handbook for research on mathematics teaching and learning. New York, NY: Macmillan, 1992. 334-370.

SCHÖN, D. The reflective practitioner: how professionals think in action. Londres: Avebury, 1991.

SCHÖN, D. Formar professores como profissionais reflexivos. Em: NÓVOA, A. (Org.). Os professores e a sua formação. Lisboa: D. Quixote, 1992. 79-91.

SOUZA, M. A. V. F. de; GUIMARÃES, H. M. A Resolução de Problemas na Educação em Matemática: uma conversa sobre ensino, formação de professores e currículo desde Pólya. Ifes Ciência, Vitória, v.1, n.1, 109-136, 2015a.

SOUZA, M. A. V. F. de; GUIMARÃES, H. M. A formulação de problemas verbais de matemática: porquê e como. Quadrante, Lisboa, v.XXIV, n.2, 135-162, 2015b.

THOMPSON, A. Teachers' beliefs and conceptions: a syntesis of the research. Em: GROUWS, D. A. (Org.). Handbook of Research on Mathematics Teaching and Learning. Nova York: MacMillan, 1992. 127-146. 